Article

\title{
Comparative Analysis of the Blood Plasma Metabolome of Negligible, Gradual and Rapidly Ageing Fishes
}

\author{
Oxana P. Trifonova *, Dmitry L. Maslov, Anton N. Mikhailov, Konstantin V. Zolotarev, \\ Kirill V. Nakhod, Valeriya I. Nakhod, Nataliya F. Belyaeva, Marina V. Mikhailova, \\ Petr G. Lokhov and Alexander I. Archakov \\ Institute of Biomedical Chemistry, 10 Building 8, Pogodinskaya Street, 119121 Moscow, Russia; \\ dlmaslov@mail.ru (D.L.M.); myhas84@mail.rub (A.N.M.); fireaxe@mail.ru (K.V.Z.); g-s2011@mail.ru (K.V.N.); \\ kardavaleriya@yandex.ru (V.I.N.); natalia.belyaeva@ibmc.msk.ru (N.F.B.); m_mikhailova@mail.ru (M.V.M.); \\ lokhovpg@rambler.ru (P.G.L.); alexander.archakov@ibmc.msk.ru (A.I.A.) \\ * Correspondence: oxana.trifonova@gmail.com; Tel.: +7-499-246-6980
}

Received: 9 October 2018; Accepted: 30 November 2018; Published: 4 December 2018

check for updates

\begin{abstract}
There are a number of different animals that belong to long- and short-lived species and show a various rate of ageing, providing an ideal model to investigate mechanisms of longevity. In this work, a metabolome profiling of blood plasma from fishes with various ageing rates-negligible (Pike Esox Lucius and Sterlet Acipenser ruthenus), gradual (Zander Sander lucioperca and Perch Perca fluviatilis) and rapid (Chum Salmon Oncorhynchus keta and Pink Salmon Oncorhynchus gorbuscha) —was assessed by means of direct infusion to quadrupole time-of-flight mass spectrometry. Of the 2056 distinct $\mathrm{m} / \mathrm{z}$ features detected by a mass spectrometry metabolic profiling of blood plasma samples, fifteen metabolites in the classes of dipeptides, fatty acids, glycerolipids, phosphoethanolamines and phosphatidylcholines were significantly associated with ageing rate, independent of species differences. This is the first study of the metabolome of fishes with various ageing rate, and this untargeted approach highlighted the metabolic conditions that may serve to assess the ageing process.
\end{abstract}

Keywords: fish; ageing; blood plasma metabolites; metabolome profiling; type of senescence; negligible ageing

\section{Introduction}

Ageing is a well-defined process for humans and many animals that is characterized by a progressive decline in physiological and reproductive capacity and increasing incidence rate and mortality over time. Nevertheless, ageing remains one of the most poorly understood biological phenomena, and there are a number of different animals that belong to the long- and short-lived species and show various rates of ageing, respectively. In 1990, C.E. Finch. proposed three categories of senescence in organisms, such as rapid senescence and sudden death, gradual senescence and definite lifespan, and negligible senescence [1]. Rapid senescence meaning death after the first round of reproduction is observed in $<1 \%$ of fish species but not in reptiles, birds, or placental mammals. Their death may be considered as an accelerated form of ageing. Most examples of rapid senescence have hormonal triggers [2]. Gradual senescence is typical for humans and other mammals. Age-related increase in mortality rate, accumulation of lipofuscin, lipid peroxidation, collagen cross-linking and decreases in growth rate, reproductive capacity and protein utilization are clearly marked in such species $[3,4]$.

C.E. Finch listed several animals, which may be described as negligibly senescent, including rockfish, sturgeon, turtles, bivalves, and possibly lobsters [1]. He further described criteria to test the 
occurrence of negligible ageing. These include the absence of an observable age-related increase in mortality rate or decrease in reproduction rate after maturity and no age-related decline in physiological capacity or disease resistance [5]. Candidates for negligible senescence are certain deep-dwelling fish with a lifespan of 100 or more years [6]. G.M. Cailliet and co-authors determined that Sebastes (rockfish) have both short-lived and long-lived members in the same genus. Their lifespan varies from 12 years for the calico rockfish to 205 years for the rougheye rockfish (Sebastes aleutianus) [7]. I. Traniello and colleagues found that the brown ghost knifefish (Apteronotus leptorhynchus) exactly fits the criteria of negligible senescence (continued growth beyond sexual maturation, and lack of reproductive senescence) and shows no signs of senescence in the brain [8]. Within mammals, naked mole-rats can be referred to negligibly senescent species. They live in captivity for more than 28 years (similar-sized mice live 3-4 years) and maintain body composition over the majority of their long lifespan showing only slight age-related changes in all physiological and morphological characteristics [9].

Studying the animals showing signs of negligible senescence may suggest effective defenses against the mechanisms underlying the degenerative process of ageing, and fishes provide an ideal model to such investigations because they show all three types of senescence. Lampreys, eels and Pacific salmonids show rapid senescence and in majority dead after first spawning. Many other teleosts including the guppy, red panchax, medaka, platyfish, and Indian murrel fish exhibit gradual senescence, as observed in most of the vertebrates. A number of fishes (e.g., sturgeons, paddlefish, female plaice, flatfish, rockfish) with continued growth and maintained reproduction over the majority of their lifespan is considered to be as very slow or negligible senescence species [10].

To this end, the well-characterized fish species with various ageing rate-negligible (Esox Lucius and Acipenser ruthenus), gradual (Sander lucioperca and Perca fluviatilis) and rapid (Oncorhynchus keta and Oncorhynchus gorbuscha) have been chosen for the comparative study. Acipenser ruthenus, as well as the other sturgeon species, has been classified as negligible ageing by Patnaik B.K. and co-authors [10]. According to that paper, one of the main signs of negligible ageing is the ability to spawn at the end of the life cycle. It is reported that the northern Esox Lucius spawns just one year before its death [11], and unlike the salmon species, which die right after spawning, the Esox Lucius is considered as a long-living fish [12]. The high-throughput metabolomics-based investigation of the three well-phenotyped cohorts of fishes with various ageing rate was intended to identify circulating blood metabolites associated with the ageing rate in these categories and assessed whether the identified metabolites were related to achieving longevity.

Metabolomics provides a promising tool to study ageing because it provides a powerful means of cataloguing changes in an organism at the molecular level over time. Through the measure of numerous small molecules that ideally represent the whole range of metabolic pathways, metabolomics can potentially aid in the identification of processes that are associated with ageing or even lead to it [13-15]. Typically ageing studies with metabolomics analyses have been conducted in animal models and have employed blood plasma as a sample that is relatively easy to obtain in a non-life-threatening manner [16-18]. Blood serum or plasma are the choice for ageing studies in humans providing novel and specific information on age-related metabolite concentration changes in human homeostasis $[19,20]$.

\section{Results}

In this study, the metabolome profiling by direct injection of a deproteinized blood plasma sample into an electrospray ion source of a hybrid quadrupole time-of-flight mass spectrometer (DI-ESI-QTOF MS) and database searching were used to compare blood plasma metabolite profiles of fishes with various rate of ageing-negligible (Esox Lucius and Acipenser ruthenus), gradual (Sander lucioperca and Perca fluviatilis) and rapid (Oncorhynchus keta and Oncorhynchus gorbuscha).

The non-targeted analytical approach detected about $6000 \mathrm{~m} / \mathrm{z}$ peaks in fish blood plasma samples. After selecting peaks, which were presented in at least $70 \%$ of the samples in each fish species group, multivariate statistics was applied. Unsupervised principal component analysis (PCA) of the 
acquired mass spectrometry (MS) spectra of the blood plasma samples for the ageing rate differences is presented in Figure 1. This score plot illustrates a reasonable clustering appearance according to assigned group membership. Principal component analysis has shown the existence of differences in metabolite plasma composition in the negligible (Esox Lucius and Acipenser ruthenus) $(\times$ ), gradual (Sander lucioperca and Perca fluviatilis) ( $\Delta$ ) and rapid (Oncorhynchus keta and Oncorhynchus gorbuscha) ( () ageing fishes. The two first components have been chosen as the most explained maximal variances between analyzed groups with clear trend explaining more than $70 \%$ of the total variance (see the upper right corner of the Figure 1).

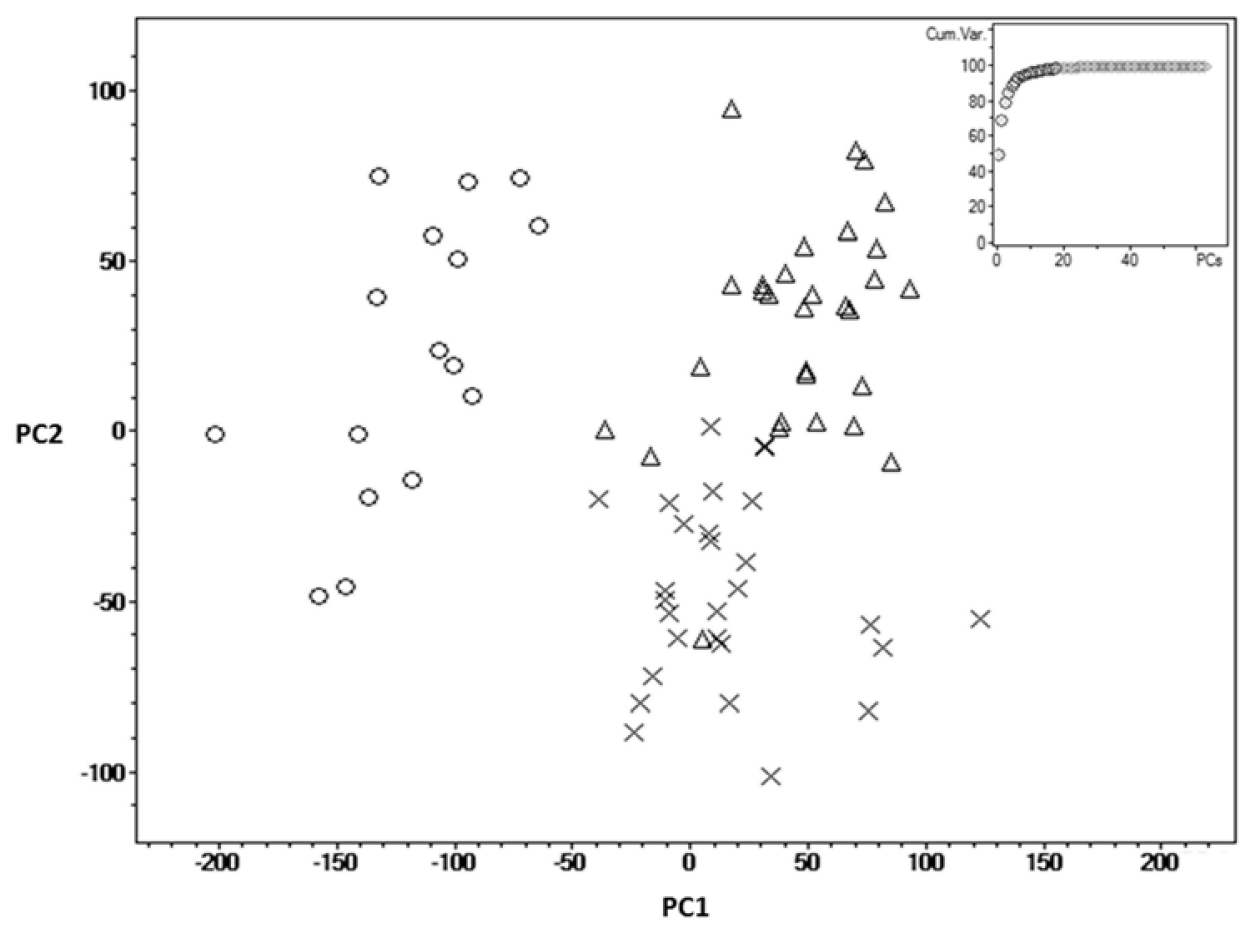

Figure 1. Discriminated PCA results of direct injection quadrupole time-of-flight mass spectrometry with an electrospray interface (source) (DI-ESI-QTOF MS) data. PCA scores plot shows the separation trends among negligible (Esox Lucius and Acipenser ruthenus) $(\times)$, gradual (Sander lucioperca and Perca fluviatilis) $(\Delta)$ and rapid (Oncorhynchus keta and Oncorhynchus gorbuscha) $(\bigcirc)$ ageing fishes. Contributions of individual variables to the separation of samples can be identified by corresponding loading plot in the upper right corner of the figure. PC: principal component.

To further classify the groups and specify the metabolic variations associated with ageing rate, it is also of some interest to compare the metabolite ions masses detected in each analyzed group. As seen in Figure 2, of the 2056 distinct $\mathrm{m} / \mathrm{z}$ features detected by mass spectrometry metabolic profiling of fish blood plasma samples, a set of 1818 ions were detected in all three groups. A total of 71 metabolite ions were common for rapid (Oncorhynchus keta and Oncorhynchus gorbuscha) and negligible (Esox Lucius and Acipenser ruthenus) ageing fishes, 47-for rapid (Oncorhynchus keta and Oncorhynchus gorbuscha) and gradual (Sander lucioperca and Perca fluviatilis) ageing fishes and 64-for gradual (Sander lucioperca and Perca fluviatilis) and negligible (Esox Lucius and Acipenser ruthenus) ageing fishes only. Comparative analysis revealed metabolite ions masses unique for each group. Thus, 34, 13 and 9 unique ions masses were exclusively detected in rapid, gradual and negligible ageing fishes, respectively. There are many possible reasons for these differences in detected metabolite ions masses among the groups. For example, the concentration of these compounds in corresponding fishes might be below detectable limits of the method. Mass spectrometry analysis and especially direct injection mass spectrometry (DIMS), depends on the ionization efficiency of analyzed molecules: the ability for a metabolite to be detected is dependent on how easily it forms either positive or negative ions. 


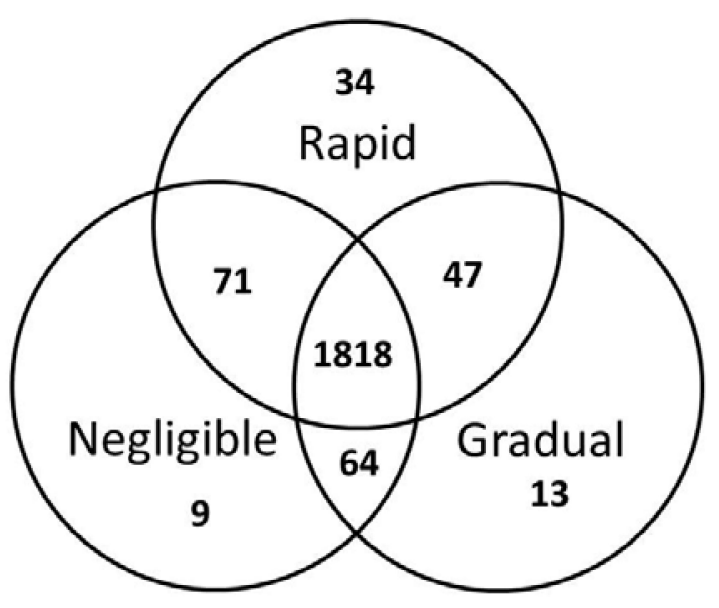

Figure 2. Venn diagram showing the overlapped and unique blood plasma metabolites ions detected by direct mass spectrometry profiling at positive mode in the samples of negligible (Esox Lucius and Acipenser ruthenus), gradual (Sander lucioperca and Perca fluviatilis) and rapid (Oncorhynchus keta and Oncorhynchus gorbuscha) ageing fishes.

The metabolite's mass spectrometry peaks, the intensity of which varies significantly $(p<0.05)$ in analyzed groups, were revealed by statistical analysis using the nonparametric Mann-Whitney $\mathrm{U}$ test. Results of the putative identification for these masses are given in Table 1. It should be noted that metabolites identification was performed by using two orthogonal characteristics as accurate mass and isotopic abundance distribution that meets level 2 (putatively annotated compounds) or in some cases level 3 (putatively annotated compound classes) of metabolite identification according to the Metabolomics Standards Initiative (MSI) [21] requirements [22,23], and for some masses there are several candidates. This is related to the fact that candidates have the same chemical formula and, consequently, identical isotope distribution that does not allow for differentiating them, but these candidates belong to the same compounds classes that fit the level 3 of metabolite identification. The putatively annotated compound classes as dipeptides, di- and triglycerides (DGs and TGs, respectively), fatty acids, phosphoethanolamines (PEs) and phosphatidylcholines (PCs) were identified in the study.

The scatter plots, presented in Figure 3, demonstrate the distribution of relative intensity of the putative metabolites (numbers correspond to Table 1) in the analyzed groups of negligible (Esox Lucius and Acipenser ruthenus) $(\times)$, gradual (Sander lucioperca and Perca fluviatilis) $(\Delta)$ and rapid (Oncorhynchus keta and Oncorhynchus gorbuscha) $(\bigcirc)$ ageing fishes. In particular, peptides and di-, triglycerides were enhanced in Oncorhynchus keta and Oncorhynchus gorbuscha, while fatty acids, phosphoethanolamines and phosphatidylcholines-in fish characterized by gradual and negligible ageing process. 
Table 1. Putative identified blood plasma metabolites characterized negligible (Esox Lucius and Acipenser ruthenus), gradual (Sander lucioperca and Perca fluviatilis) and rapid (Oncorhynchus keta and Oncorhynchus gorbuscha) ageing fishes.

\begin{tabular}{|c|c|c|c|c|c|c|c|c|}
\hline \multirow{2}{*}{ No. } & \multirow{2}{*}{ Metabolite } & \multirow{2}{*}{ HMDB ID } & \multicolumn{2}{|c|}{ Mass Of Ion } & \multirow{2}{*}{ Ion Form } & \multirow{2}{*}{$\begin{array}{l}\text { Elemental } \\
\text { Composition }\end{array}$} & \multirow{2}{*}{$p$-Value * } & \multirow{2}{*}{ Adjusted $p$-Value ** } \\
\hline & & & Measured (m/z) & Calculated (Da) & & & & \\
\hline \multicolumn{9}{|c|}{ Increased in rapid ageing fishes-Oncorhynchus keta and Oncorhynchus gorbuscha } \\
\hline & Anserine & HMDB00194 & & & & & & \\
\hline 1 & Balenine & HMDB05769 & 263.1121 & 263.1115 & $\mathrm{M}+\mathrm{Na}$ & $\mathrm{C}_{10} \mathrm{H}_{16} \mathrm{~N}_{4} \mathrm{O}_{3}$ & $0.0004 / 0.0007$ & $0.8 / 1.4$ \\
\hline & Homocarnosine & HMDB00745 & & & & & & \\
\hline 2 & $\begin{array}{l}\text { a-Glutamylalanine } \\
\text { g-Glutamylalanine }\end{array}$ & $\begin{array}{l}\text { HMDB03764 } \\
\text { HMDB06248 }\end{array}$ & 437.1883 & 437.1878 & $2 \mathrm{M}+\mathrm{H}$ & $\mathrm{C}_{8} \mathrm{H}_{14} \mathrm{~N}_{2} \mathrm{O}_{5}$ & $2.5 \times 10^{-9} / 5.1 \times 10^{-10}$ & $5 \times 10^{-6} / 1.2 \times 10^{-6}$ \\
\hline 3 & TG & N/A & 482.4210 & $\begin{array}{l}482.4199 \\
482.4212 \\
482.4224\end{array}$ & $\begin{array}{c}\mathrm{M}+2 \mathrm{Na} \\
\mathrm{M}+\mathrm{H}+\mathrm{Na} \\
\mathrm{M}+2 \mathrm{H}\end{array}$ & $\begin{array}{l}\mathrm{C}_{59} \mathrm{H}_{114} \mathrm{O}_{6} \\
\mathrm{C}_{61} \mathrm{H}_{112} \mathrm{O}_{6} \\
\mathrm{C}_{63} \mathrm{H}_{110} \mathrm{O}_{6}\end{array}$ & $2.9 \times 10^{-7} / 2 \times 10^{-7}$ & $5.8 \times 10^{-4} / 4 \times 10^{-4}$ \\
\hline 4 & DG & $\mathrm{N} / \mathrm{A}$ & 571.5068 & 571.4932 & $\mathrm{M}+\mathrm{CH}_{3} \mathrm{OH}+\mathrm{H}$ & $\mathrm{C}_{33} \mathrm{H}_{62} \mathrm{O}_{5}$ & $1.2 \times 10^{-13} / 2.8 \times 10^{-13}$ & $2.4 \times 10^{-10} / 5.6 \times 10^{-10}$ \\
\hline 5 & DG & N/A & 585.5222 & 585.5089 & $\mathrm{M}+\mathrm{CH}_{3} \mathrm{OH}+\mathrm{H}$ & $\mathrm{C}_{34} \mathrm{H}_{64} \mathrm{O}_{5}$ & $1.7 \times 10^{-8} / 1.1 \times 10^{-8}$ & $3.4 \times 10^{-5} / 2.2 \times 10^{-5}$ \\
\hline 6 & DG & $\mathrm{N} / \mathrm{A}$ & 599.5368 & 599.5245 & $\mathrm{M}+\mathrm{CH}_{3} \mathrm{OH}+\mathrm{H}$ & $\mathrm{C}_{35} \mathrm{H}_{66} \mathrm{O}_{5}$ & $9.6 \times 10^{-14} / 3.1 \times 10^{-14}$ & $2 \times 10^{-10} / 6.2 \times 10^{-11}$ \\
\hline 7 & TG & $\mathrm{N} / \mathrm{A}$ & 835.6687 & 835.6786 & $\mathrm{M}+\mathrm{Na}$ & $\mathrm{C}_{52} \mathrm{H}_{92} \mathrm{O}_{6}$ & $2.3 \times 10^{-8} / 2.2 \times 10^{-13}$ & $4.6 \times 10^{-5} / 4.4 \times 10^{-10}$ \\
\hline \multicolumn{9}{|c|}{ Increased in normal ageing fishes-Sander lucioperca and Perca fluviatilis } \\
\hline 8 & 3-Methyl-5-pentyl-2-furanundecanoic acid & HMDB31005 & 695.5190 & 695.5221 & $2 \mathrm{M}+\mathrm{Na}$ & $\mathrm{C}_{21} \mathrm{H}_{36} \mathrm{O}_{3}$ & $6.4 \times 10^{-11} / 2.5 \times 10^{-14}$ & $1.3 \times 10^{-7} / 5 \times 10^{-11}$ \\
\hline 9 & PC & N/A & 716.5602 & 716.5589 & $\mathrm{M}+\mathrm{H}$ & $\mathrm{C}_{40} \mathrm{H}_{78} \mathrm{NO}_{7} \mathrm{P}$ & $7.7 \times 10^{-5} / 0.032$ & $0.16 / 66$ \\
\hline 10 & 3,4-Dimethyl-5-pentyl-2-furanundecanoic acid & HMDB31126 & 723.5440 & 723.5534 & $2 \mathrm{M}+\mathrm{Na}$ & $\mathrm{C}_{22} \mathrm{H}_{38} \mathrm{O}_{3}$ & $1.3 \times 10^{-17} / 1.2 \times 10^{-12}$ & $2.6 \times 10^{-14} / 2.4 \times 10^{-9}$ \\
\hline 11 & PS & $\mathrm{N} / \mathrm{A}$ & 790.5723 & 790.5592 & $\mathrm{M}+\mathrm{H}$ & $\mathrm{C}_{42} \mathrm{H}_{80} \mathrm{NO}_{10} \mathrm{P}$ & $5.5 \times 10^{-7} / 0.002$ & $0.0011 / 4$ \\
\hline \multicolumn{9}{|c|}{ Increased in negligible ageing fishes-Esox Lucius and Acipenser ruthenus } \\
\hline 12 & Hexadecanedioic acid & HMDB00672 & 287.2362 & 287.2217 & $\mathrm{M}+\mathrm{H}$ & $\mathrm{C}_{16} \mathrm{H}_{30} \mathrm{O}_{4}$ & $2.4 \times 10^{-5} / 0.01$ & $0.048 / 20$ \\
\hline 13 & DG & N/A & 745.5786 & 745.5741 & $\mathrm{M}+\mathrm{Na}$ & $\mathrm{C}_{47} \mathrm{H}_{78} \mathrm{O}_{5}$ & $0.002 / 0.02$ & $4.0 / 40$ \\
\hline 14 & $\mathrm{PC} / \mathrm{PE}$ & N/A & 758.5703 & 758.5694 & $\mathrm{M}+\mathrm{H}$ & $\mathrm{C}_{42} \mathrm{H}_{80} \mathrm{NO}_{8} \mathrm{P}$ & $5.1 \times 10^{-5} / 7.0 \times 10^{-4}$ & $0.12 / 1.4$ \\
\hline 15 & $\mathrm{PC} / \mathrm{PE}$ & $\mathrm{N} / \mathrm{A}$ & 772.5870 & 772.5851 & $\mathrm{M}+\mathrm{H}$ & $\mathrm{C}_{43} \mathrm{H}_{82} \mathrm{NO}_{8} \mathrm{P}$ & $0.01 / 0.007$ & $20 / 14$ \\
\hline
\end{tabular}

diacylglycerol; PC, phosphatidylcholine; PE, phosphatidylethanolamine; ${ }^{*} p$ values were calculated from the nonparametric Mann-Whitney U test; **, adjusted $p$-value for multiple testing. 

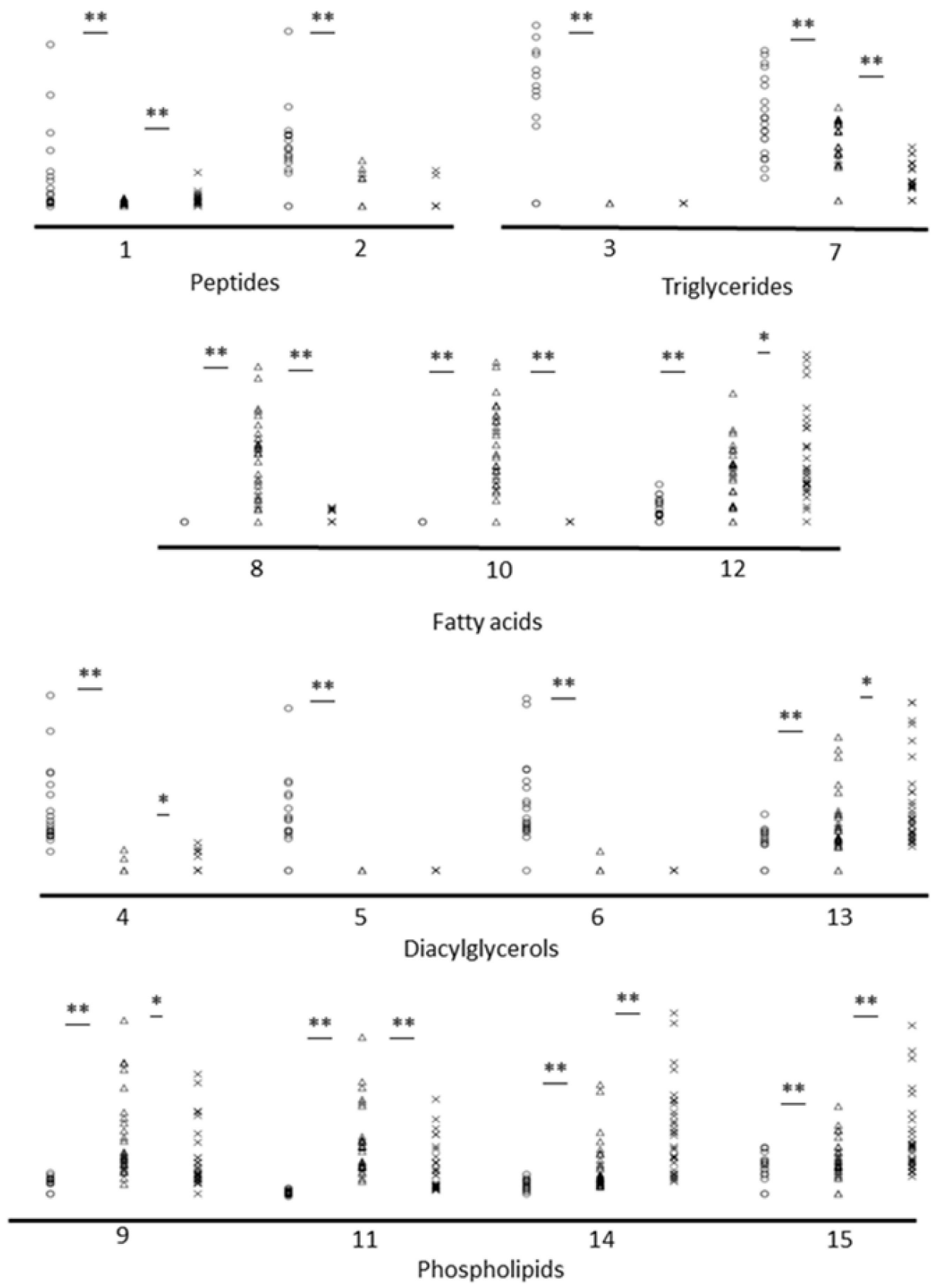

Figure 3. Results of the univariate statistical analysis, showing putative metabolites with statistically significant differences among groups-negligible (Esox Lucius and Acipenser ruthenus) $(\times)$, gradual (Sander lucioperca and Perca fluviatilis) $(\Delta)$ and rapid (Oncorhynchus keta and Oncorhynchus gorbuscha) $(\bigcirc)$ ageing fishes. Scatter plots show the relative intensity comparison of three groups in each significantly different metabolite ${ }^{*} p<0.05 ;{ }^{* *} p<0.01$ calculated from the nonparametric Mann-Whitney U test). The data represent the putative metabolites numbers corresponding to Table 1 .

\section{Discussion}

Results of the present pilot study demonstrate that the blood plasma metabolite profiles of fishes with various ageing rate differ and the revealed differences are significantly associated with ageing rate, independent of fish species. For the comparative study the well-characterized fish species with various ageing rate-negligible (Esox Lucius and Acipenser ruthenus), gradual (Sander lucioperca and Perca fluviatilis) and rapid (Oncorhynchus keta and Oncorhynchus gorbuscha) have been chosen. The pike Esox lucius is a large, long-lived (up to 30 years), top-predator fish species of the genus Esox 
with a circumpolar distribution that occupies a broad range of aquatic environments. The sterlet (Acipenser ruthenus) is a relatively small species of sturgeon of the genus Acipenser migrating between fresh and salt water and commonly reaching the age of 22 to 25 years (up to 46 years). According to Patnaik B.K. and co-authors, one of the main signs of negligible ageing is the ability to grow and spawn at the end of the life cycle [10]. Acipenser ruthenus, as well as the other sturgeon species, has been classified as negligible ageing [10]. The northern Esox Lucius spawns just one year before its death [11] and is considered as a long-lived fish [12]. The perch Perca fluviatilis, (genus Perca) is a predatory species found in Europe and northern Asia. They can live for up to 16 years. The zander Sander lucioperca (genus Sander) is a species of fish from freshwater and brackish habitats in western Eurasia with maximum lifespan of 22 years. The zander is closely related to the perch. The pink salmon (Oncorhynchus gorbuscha) and chum salmon (Oncorhynchus keta) are species of anadromous fish in the salmon family (Pacific salmon) with lifespan up to 3 and 7 years respectively. They usually die right after spawning and are classified as rapid-ageing species [10]. It should be noted that all analyzed fish species are predators. In order to neglect possible variability related to age, sex and another physiological status all studied fish species were at the adult stage and in the studied groups the species both before and after spawning were presented.

For global comparative analysis, it is important to obtain reliable data on numerous metabolites related to multiple chemical classes and metabolic pathways (metabolites profile), currently available mass spectrometry techniques with high mass resolution and accuracy are required [24]. Direct injection mass spectrometry as well as liquid chromatography-mass spectrometry (LC-MS) methods may be the best choice for such metabolomics studies of complex biofluids due to their sufficient sensitivity. Both techniques are widely used for comparative untargeted analysis (metabolite profiling), but DIMS provides a more high-throughput system for metabolite profiling, because a large number of samples can be analyzed in a given period of time, and at the same time reflects the difficulty in maintaining reproducibility of the LC-MS technique, where chromatographic drift or small changes in instrument performance can impair the data analysis [14,25].

In the present study, DI-ESI-QTOF MS of the blood plasma samples of Esox Lucius, Acipenser ruthenus, Sander lucioperca, Perca fluviatilis, Oncorhynchus keta and Oncorhynchus gorbuscha resulted in the detection of about $6000 \mathrm{~m} / \mathrm{z}$ peaks with a mass-to-charge ratio (m/z) up to $1000 \mathrm{Da}$ (data not shown), which corresponded to several hundred metabolites including quasi-molecular ions. Thus, the mass spectrometry peaks observed in the region with higher $\mathrm{m} / \mathrm{z}$ ratios $(>500)$ correspond to the high-abundance plasma lipids such as phospholipids, di- and triglycerides, and lysophospholipids. In particular, a very complex spectrum region with multiple peaks is yielded from 700 to $900 \mathrm{~m} / \mathrm{z}$ due to differences in hydrocarbon chains of fatty acids that present in phospholipids, which can differ in the exact individual fatty acyl groups present, positional distribution of fatty acyl groups, double bond location, geometry, etc. The signals in the mass spectrum region with $\mathrm{m} / \mathrm{z}$ of $450-600 \mathrm{Da}$ correspond to lysoforms of phospholipids. The region up to $400 \mathrm{Da}$ corresponds to low molecular weight metabolites of different chemical classes that are responsible for various physiological functions-amino acids, organic acids, peptides, carbohydrates etc. [26].

The obtained comprehensive dataset of 2056 mass spectra peaks reproducible in at least $70 \%$ of the samples in each fish species group (negligible-Esox Lucius and Acipenser ruthenus, gradual-Sander lucioperca and Perca fluviatilis and rapid-Oncorhynchus keta and Oncorhynchus gorbuscha) has allowed for revealing twenty three ionic species significantly associated with ageing rate, 15 of them was putatively annotated as dipeptides, di- and triglycerides, fatty acids, phosphoethanolamines and phosphatidylcholines (Table 1). It is important to note that there were no significant gender differences in metabolic blood plasma profile of analyzed species (data not shown) and analyzed features were common for both species in each group. Together with the fact that all fish species were at the adult stage and the all studied groups include the species both before and after spawning, it allows for specifying revealed metabolites as related to ageing. As shown in Figure 3, the level of two peptides (metabolites 1 and 2 in Table 1) was significantly increased in rapid ageing fishes-Oncorhynchus 
keta and Oncorhynchus gorbuscha. Anserine, a histidine-containing dipeptide, as well as its precursor carnosine mostly occurs in skeletal muscle tissue of the vertebrates. The relatively high concentration of anserine in salmonid muscle tissues have been reported by Boldyrev A.A. and co-authors [27]. Homocarnosine is mostly presented in the brain where it serves as an inhibitory neuromodulator [28]. Glutamylalanine like other glutamine-containing dipeptides may be the product of glutathione hydrolytic decomposition [29]. Glutathione is one of the main antioxidants; it is mostly presented in the liver. So, the increased level of these peptides in the blood of the breeding salmonids may be the indicator of necrosis in their skeletal muscle, brain and liver. Moreover, there are also some external indicators of necrosis: degradation of internal tissues, bruises, edemas, rotten smell, all of which were observed while sampling in the study.

The levels of triglycerides (metabolites 3 and 7) showed significant differences between negligible, gradual and rapid ageing fishes. The TG's ion with $\mathrm{m} / \mathrm{z} 482.4210$ was detected in rapid ageing fishes only (Figure 3). An increase of TGs is a typical feature of the ageing process due to the poor TG metabolism [30]. Diacylglycerol (DG) is a lipid intermediate believed to be the true lipotoxic culprit underlying the known detrimental effect of TG on many age-related metabolic disorders, e.g., atherosclerosis and diabetes. In support of this, elevated levels of DGs in the rapid ageing fishes (Figure 3 metabolites 4-6) were revealed in our study. An important aspect of ageing is the occurrence of age-related changes in biological functions involving metabolism and membrane transport, and these glycerolipids can be considered as second messengers that impair insulin and/or transmembrane signaling, both of which are known to be involved in the process of ageing [31].

Some fatty acids have been found specific for gradual ageing fishes-Sander lucioperca and Perca fluviatilis. 3-Methyl-5-pentyl-2-furanundecanoic acid and 3,4-dimethyl-5-pentyl-2-furanundecanoic acid are also known as F5 furan fatty acids and belong to the class of long-chain fatty acids [32]. Furan fatty acids exhibit potent radical-scavenging ability and anti-inflammatory efficacy, which might be responsible for the health-promoting effect. It was noted, to counteract the increased susceptibility of omega-3 rich membranes to oxidation animals like fish able to utilize special antioxidants/radical scavengers termed the furan fatty acids [33]. The level of hexadecanedioic acid (metabolite 12) - long-chain unsaturated fatty acid—was significantly increased in negligible ageing fishes-Esox Lucius and Acipenser ruthenus—as well as in gradual ageing fishes in comparison to rapid ageing fishes. As known, unsaturated fatty acids play a role in a major of biological functions as membrane transport, energy metabolism and signalling, and their concentration decreases with advancing age. Lu Y. and co-workers (2008), who used GC-MS to analyze age-related metabolic changes in the blood plasma of rats, have observed that the concentrations of several fatty acids, including linoleic acid, oleic acid, and hexadecanoic acid decrease with age (10-18 weeks) in the normotensive control-again pointing to changes in lipid metabolism with age [16]. In addition, it was found that long-chain unsaturated fatty acids can function as metabolic signals to regulate reproductive functions of the organism through their effect on the gene expression and secretion of gonadotropic hormones.

It was found that plasma levels of four metabolites (9, 11, 14 and 15) matching PCs, PS and PEs were significantly increased in gradual and negligible ageing fishes. These most abundant metabolites founded in all living organisms represent the backbone of most biological membranes. Phosphatidylethanolamines (PEs) elevated in the negligible ageing fishes are ether-linked phospholipids required for normal developmental, physiological, and cognitive functions [34]. In addition, they are proposed to act as antioxidants and may also influence intracellular signaling and membrane dynamics. For example, PE has been reported as a positive regulator of autophagy; lifespan of yeast and mammalian cell culture reportedly grew up with an increased level of intracellular PE [35].

Although the revealed differences in blood plasma abundance of metabolites can be partly associated with differences in environment and diet of the studied fish species, the fact that the detected metabolites are well consistent with already known pathophysiological mechanisms of ageing and are in full agreement with previous studies, suggesting the biological plausibility of our findings. 
Detection of the above metabolites with different levels in blood plasma of fishes with various ageing rate demonstrates the complexity of pathophysiological processes occurs in the organism with ageing and highlights a number of the related metabolic conditions that may serve to assess these processes. Blood is one of the most used biofluids in metabolomics and using blood plasma sampling for the study as a primary carrier of small molecules in the body provides information about main physiological processes, which allows for extrapolating the findings to the whole organism. However, for approving and deep insight of ageing mechanisms in studied fishes additional studies using different tissues and organs and techniques other than DIMS with electrospray ion source are needed.

\section{Materials and Methods}

\subsection{Fish, Experimental Conditions and Sampling}

For compared analysis of blood plasma metabolome of fishes with various rate of ageing the samples were collected from negligible (Esox Lucius, $\mathrm{N}=22$ and Acipenser ruthenus, $\mathrm{N}=10$ ), gradual (Sander lucioperca, N = 19 and Perca fluviatilis), N =12) and rapid (Oncorhynchus keta, N = 10 and Oncorhynchus gorbuscha, $\mathrm{N}=10$ ) ageing species [10]. The salmonid samples were freshly obtained from fishes wild-caught at Sakhalin Island; all the others were obtained from fishes wild-caught at the Uglichskoye pond during 2014-2016 years (collection permits: no. 69201403 0722, no. 69201503 0683, and no. 69201603 0737, issued by the Federal Agency for Fisheries of the Russian Federation). The study was conducted in accordance with the Declaration of Helsinki.

Table 2 presents the characteristics of the analyzed cohorts with the values of mean lifespan and pubertal timing and the highest reported age of the species being studied. Sex of all fish species was determined based on gonads (testis or ovary) [36]. Age of each fish was determined by analyzing the growth rings on the scales [37]. About ten scales were removed from the middle section of a fish body, between a dorsal fin and a lateral line. They were purified and examined using a binocular microscope. The rings that continued around the entire circumference of the scale were counted and the total number of these rings was used to estimate the age of each specimen. All fish species were at the adult stage that means that they were all ready for reproduction (they all had visible developing gonads). In all studied groups, the species both before and after spawning were presented. For all fish species, the hematology and biochemical measures (glucose, cholesterol, triglycerides etc.) were performed to show their health status (data not shown).

Table 2. Characteristics of the analyzed fish groups of Oncorhynchus gorbuscha, Oncorhynchus keta, Perca fluviatilis, Sander lucioperca, Esox Lucius and Acipenser ruthenus.

\begin{tabular}{|c|c|c|c|c|c|c|}
\hline \multirow{3}{*}{$\begin{array}{c}\text { Ageing Rate } \\
\text { Species }\end{array}$} & \multirow{2}{*}{\multicolumn{2}{|c|}{$\begin{array}{c}\text { Rapid Ageing } \\
\mathrm{N}=20\end{array}$}} & \multirow{2}{*}{\multicolumn{2}{|c|}{$\begin{array}{c}\text { Normal Ageing } \\
\mathrm{N}=31\end{array}$}} & \multirow{2}{*}{\multicolumn{2}{|c|}{$\begin{array}{c}\text { Negligible Ageing } \\
N=31\end{array}$}} \\
\hline & & & & & & \\
\hline & $\begin{array}{l}\text { Oncorhynchus } \\
\text { gorbuscha }\end{array}$ & $\begin{array}{l}\text { Oncorhynchus } \\
\text { keta }\end{array}$ & $\begin{array}{c}\text { Perca } \\
\text { fluviatilis }\end{array}$ & $\begin{array}{c}\text { Sander } \\
\text { lucioperca }\end{array}$ & $\begin{array}{l}\text { Esox } \\
\text { Lucius }\end{array}$ & $\begin{array}{l}\text { Acipenser } \\
\text { ruthenus }\end{array}$ \\
\hline Number & 10 & 10 & 19 & 12 & 21 & 10 \\
\hline Sex (male/female) & $5 / 5$ & $5 / 5$ & $\begin{array}{c}7 / 8 \\
\mathrm{~N} / \mathrm{A}^{*}=4\end{array}$ & $\begin{array}{c}3 / 6 \\
N / A^{*}=2\end{array}$ & $8 / 13$ & $8 / 2$ \\
\hline Age (years) ${ }^{\#}$ & $2.4 \pm 0.5$ & $3.4 \pm 0.5$ & $6.7 \pm 2.4$ & $4.3 \pm 1.9$ & $6.1 \pm 1.9$ & $4.0 \pm 0.4$ \\
\hline Mean Lifespan (years) \& & 2 & 5 & 10 & 7 & 12 & 22 \\
\hline Max Longevity (years) \& & 3 & 7 & 22 & 16 & 30 & 46 \\
\hline Pubertal timing (years) \& & 1 & 3 & 2 & 3 & 2 & $3-4$ \\
\hline
\end{tabular}

Blood sampling was performed by clipping of the tail and using EDTA (1.5 mg Na2EDTA per $1 \mathrm{~mL}$ blood). As sampling was performed directly at the place of fishing the tubes with collected blood were immediately placed in the fridge bag and then (15-30 min after blood sampling) taken to the lab where they were centrifuged at $1600 \times g$ for $15 \mathrm{~min}$ at room temperature and frozen before shipment 
in special thermos-containers. All centrifuged blood samples then stored at $-80{ }^{\circ} \mathrm{C}$ until analysis. Since the samples were frozen without subdivision of resultant plasma, addition centrifugation of thaw samples was performed before sample preparation.

\subsection{Blood Plasma Metabolite Extraction and Mass Spectrometry Analysis}

To remove proteins from blood plasma $10 \mu \mathrm{L}$ of the sample were mixed with $10 \mu \mathrm{L}$ of water (LiChrosolv; Merck KGaA, Darmstadt, Germany) and $80 \mu \mathrm{L}$ of methanol (Fluka, Munich, Germany), and incubated at room temperature during $10 \mathrm{~min}$. After incubation samples were centrifuged at 13,000 $\times g$ (Centrifuge 5804R; Eppendorf AG, Hamburg, Germany) for $15 \mathrm{~min}$ at room temperature, and resultant supernatants were then transferred to clean Eppendorf tubes. Before mass spectrometry analysis to each tube the fifty volumes of methanol with $0.1 \%$ formic acid (Fluka) was added to obtain the analyzed solution [40].

Mass spectrometry analysis of the samples was carried out by a hybrid quadrupole time-of-flight mass spectrometer (maXis Impact, Bruker Daltonics, Billerica, MA, USA) equipped with an electrospray ionization (ESI) source. The mass spectrometer was set up to detect ions with the mass-to-charge ratio $(\mathrm{m} / \mathrm{z})$ in the range from 50 to $1000 \mathrm{Da}$ and mass accuracy up to 3 parts per million (ppm). The appropriate mass range of the mass spectrometer was calibrated by using ES Tuning Mix (Agilent). Spectra were acquired in the positive ion mode detection. The samples were injected into the ESI source using a glass syringe (Hamilton Bonaduz AG, Bonaduz, Switzerland) and syringe injection pump (KD Scientific, Holliston, MA, USA) with a flow rate of $180 \mu \mathrm{L} / \mathrm{h}$ and in a randomized order. Mass spectra were recorded by DataAnalysis software (version 3.4, Bruker Daltonics) to summarize signals for one minute.

\subsection{Data Analysis}

Recalibration, peak detection and peak intensity and area calculation of mass spectra were performed using DataAnalysis software. Ion metabolite masses were determined from the mass spectrum peaks selected with the following parameters: peak width -5 , signal to noise ratio-2, relative and absolute threshold intensity $-0.05 \%$ and 100 respectively. Alignment of mass spectrum peaks, removal of low-informative peaks, and data correction to address the ionic inconsistency in blood plasma samples were performed by using the self-made algorithm in Excel. It was considered that two peaks relate to the same metabolite ion if their mass difference does not exceed $0.01 \mathrm{Da}$. All peaks intensity and area values were normalized by the internal standard (IS) Losartan $\left(\mathrm{C}_{22} \mathrm{H}_{23} \mathrm{ClN}_{6} \mathrm{O}\right.$, $\mathrm{m} / \mathrm{z}=423.169)$ concentration levels.

Principal Component Analysis (PCA) was performed on the acquired mass spectrometry metabolite profiling data using the ProfileAnalysis (Bruker Daltonics, Billerica, MA, USA). Contributions of individual variables to the separation of samples have been identified by corresponding loading plots and reconfirmed by nonparametric Mann-Whitney $U$ test. For the metabolite peaks, whose intensity statistically differ $(p \leq 0.05)$ in the compared groups, an average value and standard deviation for each group were calculated.

\subsection{Mass Spectra Peak Annotation}

The mass spectrometry peaks with reliably distinguished intensity in analyzed groups of samples were identified by using two orthogonal characteristics as accurate mass and isotopic abundance distribution that meets the level 2 (putatively annotated compounds) or in some cases level 3 (putatively annotated compound classes) of metabolite identification according to the Metabolomics Standards Initiative (MSI) requirements [21,22]. The measured molecular mass of the metabolite is queried against a metabolite databases "Human Metabolome Database" [41,42] and METLIN [43,44] with mass tolerance up to $0.01 \mathrm{Da}$ and allowing possible adducts in the positive ionization mode. Theoretical isotope patterns for the metabolites were generated by the Isotope Pattern Calculator (Bruker Daltonics, Billerica, MA, USA). 


\section{Conclusions}

In summary, this is the first study of the metabolome of fishes with various ageing rate and the combination of the metabolite profiling DI-ESI-QTOF MS with statistical analyses have allowed for differentiating the blood plasma samples of fish species in accordance with their type of senescence. It has been shown that the blood plasma levels of fifteen metabolites are significantly associated with ageing rate, independent of fish species. These newly detected metabolites are well consistent with already known pathophysiological mechanisms of ageing and are in full agreement with previous studies, suggesting the biological plausibility of the findings. Comprehensive utilization of these results may be of great benefit for enhanced knowledge in functional studies of the ageing process and highlighted metabolic condition may serve to assess the ageing process.

Author Contributions: Conceptualization, O.P.T., M.V.M., P.G.L. and A.I.A.; Methodology, O.P.T., M.V.M. and P.G.L.; Software, O.P.T. and D.L.M.; Validation, O.P.T., K.V.Z. and M.V.M.; Formal Analysis, O.P.T. and D.L.M.; Investigation, O.P.T., D.L.M., A.N.M., K.V.Z., K.V.N., V.I.N. and N.F.B.; Resources, O.P.T., A.N.M., K.V.Z., K.V.N., V.I.N. and N.F.B.; Data Curation, O.P.T. and D.L.M.; Writing-Original Draft Preparation, O.P.T.; Writing-Review \& Editing, O.P.T., M.V.M. and P.G.L.; Visualization, O.P.T.; Supervision, O.P.T., M.V.M., P.G.L. and A.I.A.; Project Administration, O.P.T., M.V.M. and P.G.L.; Funding Acquisition, M.V.M., P.G.L. and A.I.A.

Funding: This research was supported by the Fundamental Scientific Research program of the Russian Academy of Sciences for 2013-2020. Mass spectrometric measurements were performed using the equipment of "Human Proteome" Core Facility of the Orekhovich Institute of Biomedical Chemistry (Russia) which is supported by Ministry of Education and Science of the Russian Federation (agreement 14.621.21.0017, unique project ID RFMEFI62117X0017).

Conflicts of Interest: The authors declare no conflict of interest.

\section{References}

1. Finch, C.E. Longevity, Senescence, and the Genome; University of Chicago Press: Chicago, IL, USA, 1990; ISBN 9780226248899.

2. Finch, C.E. Variations in Senescence and Longevity Include the Possibility of Negligible Senescence. J. Gerontol. Ser. A Biol. Sci. Med. Sci. 1998, 53A, B235-B239. [CrossRef]

3. Craig, T.; Smelick, C.; Tacutu, R.; Wuttke, D.; Wood, S.H.; Stanley, H.; Janssens, G.; Savitskaya, E.; Moskalev, A.; Arking, R.; et al. The Digital Ageing Atlas: Integrating the diversity of age-related changes into a unified resource. Nucleic Acids Res. 2015, 43, D873-D878. [CrossRef]

4. Ricklefs, R.E.; Scheuerlein, A. Comparison of aging-related mortality among birds and mammals. Exp. Gerontol. 2001, 36, 845-857. [CrossRef]

5. Finch, C.E.; Austad, S.N. History and prospects: Symposium on organisms with slow aging. Exp. Gerontol. 2001, 36, 593-597. [CrossRef]

6. Finch, C.E. Update on slow aging and negligible senescence-A mini-review. Gerontology 2009, 55, 307-313. [CrossRef] [PubMed]

7. Cailliet, G.M.; Andrews, A.H.; Burton, E.J.; Watters, D.L.; Kline, D.E.; Ferry-Graham, L.A. Age determination and validation studies of marine fishes: Do deep-dwellers live longer? Exp. Gerontol. 2001, 36, 739-764. [CrossRef]

8. Traniello, I.M.; Sîrbulescu, R.F.; Ilieş, I.; Zupanc, G.K.H. Age-related changes in stem cell dynamics, neurogenesis, apoptosis, and gliosis in the adult brain: A novel teleost fish model of negligible senescence. Dev. Neurobiol. 2014, 74, 514-530. [CrossRef]

9. Fang, X.; Seim, I.; Huang, Z.; Gerashchenko, M.V.; Xiong, Z.; Turanov, A.A.; Zhu, Y.; Lobanov, A.V.; Fan, D.; Yim, S.H.; et al. Adaptations to a Subterranean Environment and Longevity Revealed by the Analysis of Mole Rat Genomes. Cell Rep. 2014, 8, 1354-1364. [CrossRef]

10. Patnaik, B.K.; Mahapatro, N.; Jena, B.S. Ageing in fishes. Gerontology 1994, 40, 113-132. [CrossRef]

11. Craig, J.F.; Kipling, C. Reproduction effort versus the environment; case histories of Windermere perch, Perca fluviatilis L., and pike, Esox lucius L. J. Fish Biol. 1983, 22, 713-727. [CrossRef]

12. Forsman, A.; Tibblin, P.; Berggren, H.; Nordahl, O.; Koch-Schmidt, P.; Larsson, P. Pike Esox lucius as an emerging model organism for studies in ecology and evolutionary biology: A review. J. Fish Biol. 2015, 87, 472-479. [CrossRef] [PubMed] 
13. Mishur, R.J.; Rea, S.L. Applications of mass spectrometry to metabolomics and metabonomics: Detection of biomarkers of aging and of age-related diseases. Mass Spectrom. Rev. 2012, 31, 70-95. [CrossRef] [PubMed]

14. Psychogios, N.; Hau, D.D.; Peng, J.; Guo, A.C.; Mandal, R.; Bouatra, S.; Sinelnikov, I.; Krishnamurthy, R.; Eisner, R.; Gautam, B.; et al. The human serum metabolome. PLoS ONE 2011, 6. [CrossRef] [PubMed]

15. He, Y.; Yu, Z.; Giegling, I.; Xie, L.; Hartmann, A.M.; Prehn, C.; Adamski, J.; Kahn, R.; Li, Y.; Illig, T.; et al. Schizophrenia shows a unique metabolomics signature in plasma. Transl. Psychiatry 2012. [CrossRef] [PubMed]

16. Lu, Y.; Wang, G.; Hao, H.; Huang, Q.; Yan, B.; Zha, W.; Gu, S.; Ren, H.; Zhang, Y.; Fan, X.; et al. Gas chromatography/time-of-flight mass spectrometry based metabonomic approach to differentiating hypertension- and age-related metabolic variation in spontaneously hypertensive rats. Rapid Commun. Mass Spectrom. 2008, 22, 2882-2888. [CrossRef] [PubMed]

17. Yan, S.; Wu, B.; Lin, Z.; Jin, H.; Huang, J.; Yang, Y.; Zhang, X.; Shen, Z.; Zhang, W. Metabonomic characterization of aging and investigation on the anti-aging effects of total flavones of Epimedium. Mol. Biosyst. 2009. [CrossRef] [PubMed]

18. Nevedomskaya, E.; Meissner, A.; Goraler, S.; De Waard, M.; Ridwan, Y.; Zondag, G.; Van Der Pluijm, I.; Deelder, A.M.; Mayboroda, O.A. Metabolic profiling of accelerated aging ERCC1d/-mice. J. Proteome Res. 2010. [CrossRef]

19. Lawton, K.A.; Berger, A.; Mitchell, M.; Milgram, K.E.; Evans, A.M.; Guo, L.; Hanson, R.W.; Kalhan, S.C.; Ryals, J.A.; Milburn, M.V. Analysis of the adult human plasma metabolome. Pharmacogenomics 2008. [CrossRef]

20. Yu, Z.; Zhai, G.; Singmann, P.; He, Y.; Xu, T.; Prehn, C.; Römisch-Margl, W.; Lattka, E.; Gieger, C.; Soranzo, N.; et al. Human serum metabolic profiles are age dependent. Aging Cell 2012. [CrossRef]

21. The Metabolomics Standards Initiative (MSI) Home Page. Available online: http:/ /www.metabolomics-msi. org/ (accessed on 4 December 2018).

22. Sumner, L.W.; Amberg, A.; Barrett, D.; Beale, M.H.; Beger, R.; Daykin, C.A.; Fan, T.W.M.; Fiehn, O.; Goodacre, R.; Griffin, J.L.; et al. Proposed minimum reporting standards for chemical analysis: Chemical Analysis Working Group (CAWG) Metabolomics Standards Initiative (MSI). Metabolomics 2007. [CrossRef]

23. Dunn, W.B.; Erban, A.; Weber, R.J.M.; Creek, D.J.; Brown, M.; Breitling, R.; Hankemeier, T.; Goodacre, R.; Neumann, S.; Kopka, J.; et al. Mass appeal: Metabolite identification in mass spectrometry-focused untargeted metabolomics. Metabolomics 2013, 9, 44-66. [CrossRef]

24. Trifonova, O.; Lokhov, P.; Archakov, A. Postgenomics diagnostics: Metabolomics approaches to human blood profiling. OMICS 2013, 17, 550-559. [CrossRef] [PubMed]

25. Barrett, D. Advances in metabolic profiling. Bioanalysis 2012, 4, 643-644. [CrossRef] [PubMed]

26. Lokhov, P.G.; Dashtiev, M.I.; Moshkovskii, S.A.; Archakov, A.I. Metabolite profiling of blood plasma of patients with prostate cancer. Metabolomics 2010, 6, 156-163. [CrossRef]

27. Boldyrev, A.A.; Aldini, G.; Derave, W. Physiology and Pathophysiology of Carnosine. Physiol. Rev. 2013, 93, 1803-1845. [CrossRef] [PubMed]

28. Petroff, O.A.C. Book Review: GABA and Glutamate in the Human Brain. Neuroscientist 2002, 8, 562-573. [CrossRef]

29. Kalhan, S.C.; Guo, L.; Edmison, J.; Dasarathy, S.; McCullough, A.J.; Hanson, R.W.; Milburn, M. Plasma metabolomic profile in nonalcoholic fatty liver disease. Metabolism 2011, 60, 404-413. [CrossRef]

30. Hamilton, M.T.; Areiqat, E.; Hamilton, D.G.; Bey, L. Plasma triglyceride metabolism in humans and rats during aging and physical inactivity. Int. J. Sport Nutr. Exerc. Metab. 2001, 11, S97-104. [CrossRef]

31. Greer, E.L.; Brunet, A. Signaling networks in aging. J. Cell Sci. 2008, 121, 407-412. [CrossRef]

32. Igoe, R.S. Dictionary of Food Ingredients, 1st ed.; Springer US: New York, NY, USA, 1996; Volume 7, ISBN 9781441997135.

33. Spiteller, G. Furan fatty acids: Occurrence, synthesis, and reactions. Are furan fatty acids responsible for the cardioprotective effects of a fish diet? Lipids 2005, 40, 755-771. [CrossRef]

34. Brites, P.; Waterham, H.R.; Wanders, R.J.A. Functions and biosynthesis of plasmalogens in health and disease. Biochim. Biophys. Acta Mol. Cell Biol. Lipids 2004, 1636, 219-231. [CrossRef]

35. Rockenfeller, P.; Koska, M.; Pietrocola, F.; Minois, N.; Knittelfelder, O.; Sica, V.; Franz, J.; Carmona-Gutierrez, D.; Kroemer, G.; Madeo, F. Phosphatidylethanolamine positively regulates autophagy and longevity. Cell Death Differ. 2015, 22, 499-508. [CrossRef] [PubMed] 
36. Devlin, R.H.; Nagahama, Y. Sex determination and sex differentiation in fish: An overview of genetic, physiological, and environmental influences. Aquaculture 2002, 208, 191-364. [CrossRef]

37. Tesch, F.W. Age and Growth. In Methods for Assessment of Fish Production in Fresh Waters; Ricker, W.E., Ed.; Blackwell Sci. Pub. IBP: Hoboken, NJ, USA, 1968; pp. 93-123.

38. AnAge: The Animal Ageing and Longevity Database. Available online: http://genomics.senescence.info/ species / (accessed on 4 December 2018).

39. Carey, J.R.; Judge, D.S. Life Spans of Mammals, Birds, Amphibians, Reptiles, and Fish; Odense University Press: Odense, Denmark, 2000; ISBN 87-7838-539-3.

40. Lokhov, P.G.; Trifonova, O.P.; Maslov, D.L.; Balashova, E.E.; Archakov, A.I.; Shestakova, E.A.; Shestakova, M.V.; Dedov, I.I. Diagnosing impaired glucose tolerance using direct infusion mass spectrometry of blood plasma. PLoS ONE 2014, 9. [CrossRef] [PubMed]

41. Human Metabolome Database. Available online: http://www.hmdb.ca (accessed on 4 December 2018).

42. Wishart, D.S.; Jewison, T.; Guo, A.C.; Wilson, M.; Knox, C.; Liu, Y.; Djoumbou, Y.; Mandal, R.; Aziat, F.; Dong, E.; et al. HMDB 3.0-The Human Metabolome Database in 2013. Nucleic Acids Res. 2013, 41. [CrossRef]

43. METLIN. Available online: http://metlin.scripps.edu/ (accessed on 4 December 2018).

44. Smith, A.; O'maille, G.; Want, E.J.; Qin, C.; Trauger, S.A.; Brandon, T.R.; Custodio, D.E.; Abagyan, R.; Siuzdak, G. METLIN A Metabolite Mass Spectral Database. Proc. Int. Congr. Ther. Drug Monit. Clin. Toxicol. 2005, 27, 747-751. [CrossRef]

(C) 2018 by the authors. Licensee MDPI, Basel, Switzerland. This article is an open access article distributed under the terms and conditions of the Creative Commons Attribution (CC BY) license (http://creativecommons.org/licenses/by/4.0/). 